\title{
NERC scheme criticized
}

SIR-Sir Ronald Fisher once remarked that research students are the most important people in a university, so that the mechanism used by research councils for the award of research studentships is bound to be of great interest. The Natural Environment Research Council (NERC) has recently published a report of a committee under Professor R.J. Berry to review its own much criticized "project method" (Report of the Research Studentship Allocation Review Committee, -November 1984).

By contrast, the Science and Engineering Research Council (SERC) has always allocated (as NERC formerly did) a num. ber of studentships to individual university departments. Undergraduates apply to departments, are chosen for their potential quality and themselves choose the field of research in which they would like to work and thus their supervisor. NERC's scheme, introduced some years ago, gives a central role to its four training awards committees, each of which receives from each department in its field a list of 10-20 projects. The geological sciences training awards committee, for example, receives about 600 projects to which, in a two-day meeting, it allocates about 100 studentships. Two practical difficulties have emerged. Students may wish to work in a department on a project that happens not that year to have been designated, while the department may not be able to find anyone that year who wishes to work on the projects chosen.

There are more fundamental objections to the scheme. It removes from university departments to these committees an essential educational role. I have also argued (Nature 271, 704; 1978 and The Observatory 102,$164 ; 1982$ ) that the ratio of geophysical to geological studentships is too small both for scientific advance and for national needs. The reason appears to be that there are many more geology than geophysics departments in universities and geophysics is still mistakenly equated with subdivisions of geology, such as stratigraphy, rather than being considered as an equal discipline: the Training Awards Committee consists of about 16 members, only one of whom is essentially a geophysicist. So the more fundamental aspects of geophysics as compared with those aspects closely related to crustal geology are under-represented in the projects chosen.

The Berry Committee consisted of the present and former chairmen of the geological science training awards committee, two former secretaries of the Medical and Agricultural Research Councils and Professor J.F. Dewey, who recently resigned from NERC's council (Nature 313, 730; $1985)$. It invited views on the project method and included a number of these in its report. From geology and geophysics departments, there are 13 against and 4 for the scheme, but from the biological departments there are 10 for and 5 against. This asymmetry, not commented upon, may well arise because, for geoscience departments, the NERC scheme is the only way of supporting research students, whereas all biological departments also obtain research students from SERC.

The committee does not meet the criticisms of the NERC scheme raised by its respondents. For example, a geology professor states: "To anyone with a knowledge of the strength of geological sciences departments within the UK, the distribution of earmarked awards between them does not look sensible; major departments with high quality staff and vigorous research schools that are known to provide first-class research training are being underused for this purpose". The committee does not meet this criticism, but instead discusses what constitutes research training.

Further, NERC's statement that "the primary objective of a research studentship is to enable the student to receive a good training in research, not to undertake a piece of novel research in a highly professional manner" was described by one geologist as badly worded, ambiguous and thoroughly misleading. The committee attempts to clarify this by specifying ten elements of research training, of which I quote three verbatim: "The definition of questions in order to be able to (a) disprove scientific hypotheses and (b) aid practical decisions; selection of materials for analysis, bearing in mind the possibilities of bias and the requirement for quality; the opportunity of obtaining an advanced understanding of an area of science via an in depth investigation of an appropriate research problem".

Further obscure and ungrammatical verbiage occurs when the committee gets exercised on how to prevent $\mathrm{PhD}$ students untidily overrunning the allocated three years. It offers the following gems of wisdom: "These [procedures] include the drawing up of a realistic timetable which must be adhered to; the fact that three years is not a very long time; the importance of avoiding a slow start; the delays caused by failure to bring to a conclusion and distraction from the main line of enquiry. We commend these practices."

Apparently some ill-natured people have raised the possibility that committee members stand a better chance than others of getting their projects approved. The tone of the report, so far unshakeably complacent, becomes somewhat agitated on this point. "The evidence of inequality was not conclusive. . . the statistics are contradictory and open to different interpretations. . Council takes a very serious view. . . an important area which should be carefully monitored in the future."
These mysterious statistics are not produced, but no matter; "members (of the awarding committee) are drawn from amongst the best research workers and a statistically higher than average award rate is to be expected"!

Finally, the committee uses the venerable tactic of putting up a lot of Aunt Sallies, "numerous misconceptions" as it calls them. "The student is unimportant; the system is complex. . . time wasting. . . difficult to understand. . . disregards best students. . . disregards students who are innovative, favours particular supervisors and/or departments committee membership is self perpetuating; topics are very narrow." I cannot imagine any member of a university staff making such crude and sweeping criticisms except in moments of exasperation (which I am reliably told sometimes occur in dealings with NERC). The Berry committee has of course no difficulty in knock ing them down, and comes to the conclusion that, except for minor alterations, no fundamental change in the scheme should be made. Dr J.C. Bowman, secretary of NERC, expresses in a preface "great pleasure in commending this report to all concerned with postgraduate training and research and sciences of the natural environment", finding it "gratifying". In NERC's eyes the scheme's virtue, as the report reveals, is that it can be represented to Whitehall as showing that university research is being guided in "relevant" directions.

Many will think this is not a recommendation and this "effortful, cumbersome, expensive and unsatisfactory scheme" should be abandoned and the considerable savings in cost used to support additional students.

School of Physics,

KeITH RunCORN

The University,

Newcastle upon Tyne NE1 7RU, UK

\section{Naked beauties}

SIR-We read with naive interest but great expectation the article by D.J. Miller, "Naked beauty seen at last", under the heading of "Particle physics", which purports to explain why a beauty quark, otherwise known as a bottom, is difficult to perceive in its naked state (sic) (Nature 316, 681; 1985). We wonder whether other biologists reading this article similarly found it tantalizing, hilariously funny and totally incomprehensible. Do particle physicists have the same response to antiidiotype networks (compare Mitchison's article in the same issue of Nature, p. 676)?

Kathy WeILbaecher MELVyn F. Greaves

Leukaemia Research Fund Centre at the Institute of Cancer Research, Chester Beatty Laboratories,

Fulham Road,

London SW3 6JB, UK 